\title{
The origins and adaptations of English as a school subject (8,362 words on 5-4-18)
}

\section{Introduction}

This chapter will consider the particular manifestation of English as a 'school subject', principally in the country called England and using some small space for significant international comparisons, and it will mainly focus on the secondary school version. We will call this phenomenon School Subject English (SSE). The chapter will argue that historically SSE has gone through phases of development and adaptation, some aspects of these changes inspired by new theories and concepts and by societal change, some others, especially more recently, are entirely reactive to external impositions. It considers SSE to have been ontologically 'expanded' between 1870 and (about) 1990, increasing the ambition and scope of the 'subject' and the emancipatory ideology of its teachers. This ontological expansion was principally a result of adding 'models' of SSE, models that each emphasise different epistemologies of what counts as significant knowledge, and can only exist in a dynamic tension. In relation to this volume, SSE has always incorporated close attention to language but only very briefly (1988-1992) has something akin to Applied Linguistics had any real influence in the secondary classroom. However, with varying emphasis historically, there has been attention (The Adult Needs/Skills model, see below) to the conventions of language, especially 'secretarial' issues of spelling and punctuation, some understanding of grammar, and a focus on notions of Standard English, in writing and in speech; but these have never been the driving ideology of SSE. Of the two conceptual giants 'Language' and 'Literature', it is the latter that has mattered most over those 120 years.

As with all education systems a particular element, such as a school subject, has become truly important once it becomes formally assessed. Literature has been recognised in this way for many decades at school and university level. England has long held a tradition of examining almost all 16 year olds [currently called GCSE] and SSE is a compulsory subject and has always included considerable attention to grammar and spelling. For 18 year olds the tradition has become to specialise to three or four subjects at 'Advance Level', these qualifications have always been seen as decisive in indicating if a student is capable of moving on to degree level. The relatively recent growth of English Language at Advanced Level is a significant but minor evolution, probably less significant than the very rapid growth of Media Studies, at GCSE, ' $A$ ' level and degree level in many universities.

SSE does exist, to an extent, in primary schools (in statutory terms from 1989) and this will be touched on but there will more consideration of English also as the 'discipline' of HEE (Higher Education English) that is fundamentally where SSE began, principally influenced by the ontologies of the university subject. There is only modest space to consider SSE from a more global perspective but there are many fascinations in the ontological status of SSE in, for example, the obvious major English speaking countries which include the US, Canada, Australia, New Zealand and Ireland, with a profound historical relationship to England and 'English'. These countries have enough in common for there to be shared theoretical constructs of SSE and practical similarities, meaning that there is a sharable history, specifically of SSE, with some key figures having powerful influences at the conceptual and the classroom level in different countries. Those countries were 'colonies' but SSE has a much more fraught existence in say the Caribbean or Gibraltar and an extraordinarily powerful 
place in nation states such as India and Singapore. The unquestionable global dominance of English as the language of communication in so many countries, means that a 'hybrid' SSE also exists there as a second language for many millions of students. In order, therefore to have any depth of analysis in examining SSE, there must be a necessarily microscopic focus upon it in England and an acceptance that such an attempt is rather like a clinical post mortem, hygienic and sterilised, whilst the dynamic organism itself continues its energetic and messy evolution in the 'real world'.

In considering that ongoing evolution, I attempt to trace the principal origins and the 'coming into being' of the 'quicksilver' (Dixon, 1975) school subject of English and its development in the $20^{\text {th }}$ century. Dixon's metaphor is based on the fact that 'quicksilver' is the popular name for Mercury, a liquid metal at room temperature that can be poured into a container of any shape. It is also a beautiful silver and the 'quick' comes from the Latin for 'living'. As this chapter shows the debate about 'what is English and what are its elements' still continues.

Any discussion of SSE must be framed socially and politically as it has been consistently the focus of political debate much reported in the media, increasingly regulated by the nation state, hence there are numerous official reports and documents, and, in the last third of the century and early $21^{\text {st }}$, constant and direct 'interference' into how SSE should be defined. This is also a global phenomenon (Goodwyn, 2011a, 2011b, 2017). Equally SSE was part of the lived experience of almost every English citizen (and therefore politician) and so becomes part of a living memory, generating endless views and opinions about what SSE is now but refracted through vaguely recalled school experiences.

Some of SSE's relentless public attention is partly explained by its pre-eminence as the basis for literacy (a term that only really enters the debate in the late $20^{\text {th }}$ century and remains in itself a debatable term (Goodwyn \& Fuller, 2011c)). SSE also has a dominating concern with literature as a cultural force, in part a form of heritage project infused with the nationalism of being 'British' (actually mostly English), therefore what texts are chosen from the literary canon captures public and political attention at every iteration.

It is also a key 'credential' with one of the highest 'values' as a 'qualification'. In fact, not to have an English qualification (at whatever is the agreed contemporary benchmark, for example, from about 1989-2016 a 'C' at GCSE) was a major detriment to life chances; for example, a 'D' grade meant being barred from becoming a teacher at primary level or of ANY subject in secondary. It has always been a key subject, but from 1989 (see below) the National Curriculum made it an explicitly compulsory subject for all students from ages 5-16. Therefore, even students who were not entered for a GCSE at 16 had to study SSE throughout their compulsory schooling. Schools even then retained control over the timetable, so how many lessons per week were involved is not officially recorded. I would suggest, based on working with a very large number of secondary schools over the last 30 years, that about 3 to 4 hours per school week were devoted to SSE and perhaps 1 to 2 of homework, so using the typical school year of 39 weeks, a 'typical student' in their 5 years experienced about 1,000 hours of SSE, which works out as perhaps 15 per cent of their school time.

The exact figure is of no real importance, the point is that SSE therefore has a huge place in the mind of the nation, regardless of their class, gender or ethnicity, and is a powerful collective memory of schooling; this is not just a feature of England but certainly of all the major English speaking countries. It is worth commenting on the additional ontological tension existing in, say the US, 
where English is the main language of the nation (although there is much discussion that it might have been German, when Congress in 1795 considered printing laws in English and German) but the official language is a variant on British English i.e. 'American English' and where high school students take British Literature courses separately from American Literature. In the US (and Canada), SSE tends actually to be called 'English and the Language Arts'. In Australia teachers of SSE are often called teachers of English and Literacy and they approve of this conjunction. In contrast, one finding from my research (Goodwyn, 2003, 2004), was that teachers in England passionately rejected being labelled as teachers of Literacy. It might be argued, by some, that Maths has equal status, but I would argue (see below) that it does not in England - it may well in other cultures, hence Shanghai's premier global league status (see OECD, PISA, 2015 [PISA is The Programme for International Students Assessment] ). One factor, put simply, is that SSE has 'double weight', there being two SSE credentialisers, one is 'English' (usually a combination of Language and Literature) but also a separate 'English Literature'.

Finally, this chapter summarises 120 years of history and change and is necessarily selective and, in some ways, unavoidably reductive of important complexities.

\section{SSE in the past and present tense}

When viewed historically, the discipline of English is considered to somehow materialise in HEE form in the mid to late nineteenth century (see below). However, in an ontological sense, the version that still prevails today had most of its origins in the 1920s, crucially coming after the devastation of the First World War with The Cambridge School (Leavis, Thompson, I.A. Richards et al) declaiming the sanctity of Literature for an elite reader. There was a paradigm shift after the Second World War because of the reaction to the elitist version by The London School in the 1960s and 70s (Britton, Barnes, Rosen et al, 1971) arguing for the primacy of language, including Speaking and Listening, a repudiation of elitism and foregrounding of the everyday language of the urban working class. However, the 'turn to language' did not in terms of SSE's existence, replace it, instead it added on new facets.

It is important here to turn to a distinction that is both epistemological and ontological i.e. how it exists but also what is it's knowledge. SSE can be considered to exist principally in two forms of knowledge. The most accessible form is historical and textual, we might call it 'the textual domain' whether it is books about English (e.g. by F. R. Leavis), reports about English (e.g. Newbolt, 1921) or a myriad syllabuses now called 'specifications' and, in a different way, a thousand dusty text books; this now also includes a myriad of web sites whose rapid changes mean that texts are constantly replaced and 'disappeared' as policy changes. All these texts have some significance - a few have great significance e.g. Dixons' Growth Through English discussed below. In all these texts we find explicit or implicit ideologies of SSE that we can analyse and deconstruct. But in the community of practice that exists always in the present tense we have the practical knowledge of the English teachers and of their students. This knowledge for the teachers is both 'subject knowledge' but also what Shulman (Shulman, 1986, 1987) has defined as 'Subject Pedagogical Knowledge', knowing how to make SSE learnable for students. In that sense SSE 'happens' in real time in a myriad of classrooms enacted and embodied by teachers and students in what is, almost all of the time a private drama, between the one teacher and the many headed class, this is the 'existential domain'. 
The students, as mentioned above, keep that version of SSE in their unreliable memories where it will resonate as they become, for example, a parent or a politician.

Over a career in teaching, the wise teacher accumulates a deep and profound knowledge of SSE, becoming an expert in its enactment. Perhaps the one place where the 'living' SSE and the textual SSE are almost indistinguishable is, for the teacher, in the more ephemeral texts of the lesson plan, the scheme of work, the work sheet and multiple visualisations that adorn all classrooms: for the students it is the 'work' of SSE, their stories, their essays, at some point literally 'marked' by their teacher. So, to make an obvious but crucially important epistemological distinction, for all the enduring importance of the 'significant' texts and their very real influence in, and on, the classroom, SSE exists in the private dramas of lessons and memories of the participants.

Given all these complexities, it makes sense to start in 'media res' with the climacteric year of 1989, in some ways a simple and specific moment as the year when the state of England took strong control of the state of SSE and, in a sense, sought to become the owner of its ontological status.

\section{Models of English?}

This highly significant moment in the history of SSE occurred in 1989 when the very first National Curriculum for English was published, carrying with it the legal apparatus of being 'statutory'. It is worth noting that the construction of a National Curriculum is a global phenomenon but by no means a universal one and subject to many and different controversies. Federal countries, e.g. the US and Australia, do their prescribing about SSE at state level; e.g. 'Victorian English' in Melbourne is the version of the state of Victoria not some old and long dead queen. They are still arguing in Australia whether there really is an Australian literature, never mind what you teach in high school.

The story of how this version of SSE in England (and technically Wales) came into being is a story in itself, one version of which has been written by Brian Cox, the committee chair and lead author of The Cox Report (see Cox, 1991 and 1992)). One very striking claim of Cox and his committee was that, in 1988 when the document was being written, there were 'Five Models of English'. They claimed that these 'models' were understood and used by all English teachers.

The term 'model', as any linguist will tell you, can be defined in many ways, perhaps the simplest explanation is that a model is usually a concrete representation of something else or, a version, as in 'this is the new model'. However, it also implies 'modelling', showing what is best or to be emulated. One reason why the Dixon book was so important was that he chose to discuss [without definition of the term] three 'models of English', I have argued he means versions (Goodwyn, 2016, 2017), Dixon argued emphatically that the Personal Growth was THE best version of English.

So the Cox committee simply adopted the term 'model', drawing (without acknowledgement or revised definition) on Dixon. They made a bold claim, based, as it was, on no real research but simply on much conversation and consultation with the profession.

Their models were:-

1. A "personal growth" view focuses on the child: it emphasises the relationship between language and learning in the individual child, and the role of literature in developing children's imaginative and aesthetic lives. 
2. A "cross-curricular" view focuses on the school: it emphasises that all teachers (of English and of other subjects) have a responsibility to help children with the language demands of different subjects on the school curriculum: otherwise areas of the curriculum may be closed to them. In England, English is different from other school subjects, in that it is both a subject and a medium of instruction for other subjects.

3. An "adult needs" view focuses on communication outside the school: it emphasises the responsibility of English teachers to prepare children for the language demands of adult life, including the workplace, in a fast-changing world. Children need to learn to deal with the day-to-day demands of spoken language and of print; they also need to be able to write clearly, appropriately and effectively.

4. A "cultural heritage" view emphasises the responsibility of schools to lead children to an appreciation of those works of literature that have been widely regarded as amongst the finest in the language.

5. A "cultural analysis" view emphasises the role of English in helping children towards a critical understanding of the world and cultural environment in which they live. Children should know about the processes by which meanings are conveyed, and about the ways in which print and other media carry values.

(Cox, 1991, the numbers are my own)

The section outlining the models was just a few paragraphs in a very lengthy document (DES, 1989), but it was a rare attempt to 'capture' the subject paradigm succinctly. It seemed to me, at the time and still now, that these 'Cox models' deserved real acknowledgement and also some challenge.

The work of the two previous decades had generated some other versions, indeed one of the most well known was Barnes et al Versions of English, published in 1984 (Barnes and Barnes). It was especially important because it was based on a three year study based in six schools and four Further Education colleges, focusing essentially on 15-17 year olds. It, in turn, owed much to Dixon's Growth Through English, first published in 1967 (Dixon, 1967). That text is a perfect illustration of how debate and discussion lead to new knowledge (Goodwyn et al. forthcoming 2018), as it followed on from the 'Dartmouth' seminar held in the USA. At this seminar, leading figures from around the English speaking world met to debate the nature and purpose of the subject. Dixon's seminal book was the outcome as it attempted to capture how the subject English was conceptualised in England.

\section{Looking back to the grand narrative}

I now attempt a summary and selective ontological history of English as a subject, principally SSE. There are plentiful histories of the origins of English as a 'discipline' and plenty of disagreements (see, for example Eagleton, 1975) about how it came into being. For our purposes in understanding how Cox could posit 5 models of English, we will briefly examine three phases of emergence and note their key 'theorists' ('ideologues' may be a better descriptor). My terms for the early phases are: 1 , ennobling the vernacular; 2 , conventions and conditions; 3 , culturing the citizenry' later we move on to 4, Growth through Language, 5, English in harmonious practice and to the present day, 
6, Building the Panopticon, the coming of control, conformity and self-regulation. I speculate, finally, on the hope for a new and emancipatory phase.

Compulsory, state education in England began in 1870, before that schooling was the privilege of the elite and essentially private, these schools confusingly were (and still are) called public schools. Their curriculum was dominated by studying Classical texts from Greek and Roman literature in ancient Greek and Latin. Such knowledge was the mark of a gentleman, attention to language in use was focused on rhetoric, the vernacular language and literature were considered vulgar; English did not exist as a subject at any level of education.

Phase 1, ennobling the vernacular, is marked by the displacement of the Classics and emergence of the vernacular in both linguistic and literary terms, approximately the 1850 s to 1914 . This period is marked by English becoming first an HEE and then, increasingly an SSE, not least because from 1870 onwards going to school became a normative part of English culture. The extraordinarily influential figure of Matthew Arnold, poet, critic and essayist but also school inspector, lights up this period with his passionate espousal of English Literature as the birth right of all citizens. By 1914 English has emerged as a substantive HEE with a professoriate and some academic credibility and SSE has become a normal subject in ordinary schools, although England's (private) 'public schools' retained a largely classical culture. Cox's Model 4, Cultural Heritage, is emerging with some attention to 3 , Adult Needs, but the school system does not yet look beyond the elementary stages.

Phase 2, conventions and conditions approximates 1918 to 1954 . One reaction to the Great War was the Newbolt Report (HMSO, 1921), named after the minor poet who chaired the committee. In terms of SSE this Report marks a point by which English has come into being with its schoolish characteristics. Those characteristics are explicated into what became known later as the four language modes, reading, writing, speaking and listening. A simple but profound point is that all four were considered both 'teachable' and 'necessary': the state was simultaneously adopting universal literacy as an entitlement and demanding that its citizens conform to using 'good' English in writing and in speech. One member of the committee was George Sampson, who produced 'English for the English' which is a very powerful argument for the centrality of SSE and for the relocation of the classics of Latin and Greek to the category of 'exotics'. His English for the English: $a$ chapter on national education, provides a passionate argument for an 'Adult Needs' model of English, for a literate nation who understand and can use 'Standard English' (Sampson, 1922).

Culturing the citizenry, Phase 3, runs from 1929 to 1954 . In 1929, I.A. Richards published Practical Criticism (1929), a follow up to his 1924 Principles of Literary Criticism (1924), and F.R. Leavis married Queenie Leavis, having recently secured a position at Downing College, creating a formidable union and part of what later became the Cambridge School of English (Gibbons, 2017). This School of Thought, was united by a fierce advocacy, especially from Leavis, of the supreme value of studying English Literature imbued with a strong evangelical spirit of its moral integrity.

Richards grappled theoretically with the nature of literary response and with what later morphed into both New Criticism in one direction, and its opposite direction, reader response theory (see Rosenblatt, 1938/1970). But Practical Criticism was a genuinely empirical study of 'real' readers - as much as Cambridge undergraduates in the 1920 s can be considered real readers - what matters was that they could not read 'properly' if left to their own devices. What Richards did was simply to give the students unseen passages and poems to evaluate and write about with no author or contextual 
information. As a result, Richards formulated his 10 difficulties in the making of meaning and quite brilliantly problematised how we make our meaning from literary texts and therefore inviting the English teacher to develop a kind of literary pedagogy. He makes specific reference to Sampson's book and to the importance of English teachers (Richards, 1929). Richards also accidentally invented the extraordinarily enduring practice suffered/enjoyed since by millions of students of literature all around the world, of doing 'practical criticism', that is reading a passage from a text, or a complete poem, with no indication of author or date and 'making a meaning'.

The Leavis' marriage was the beginning of a new critical force, imbued with a version of Richards' practical criticism which became 'close reading' of 'the words on the page'. For F.R. Leavis in particular, coming from his stern non-conformist background, this also became a moral and evangelical campaign to elevate HEE to be the most important of all university subjects and no less than the saviour of a declining civilisation constantly corroded by the emerging powers of the mass media. This was captured most neatly in his textbook for SSE teachers and students, published in 1933 Culture and Environment (Leavis and Thompson), which launched his battle cry, discriminate and resist! Leavis, in texts such as The Great Tradition, argued for the supremacy of English Literature over all other literatures and therefore making it the most important subject to study at university. In that sense he was imbuing Cultural Heritage with a profound Englishness that persists to this day and is currently enshrined in both official documentation (DfE, 2018) and all the specifications of the examination boards, credentialising the English Cultural Heritage.

However, one unintended consequence of Leavis' taking the effects of the popular media so seriously was, unwittingly, to invent 'Media Studies', a discipline that emerged powerfully in the 1960s, sometimes called 'Cultural Studies'. It can therefore be argued that Leavis' cocktail version of Richards' theories of reading and invention of practical criticism engendered Model 5, Cultural Analysis. The stance, 'discriminate and resist', was later reconceptualised as 'Inoculation theory' (see Goodwyn, 1992b) and certainly English teachers, who have long held very mixed views of the popular media, generally share an ideological stance in which Cultural Heritage and Cultural Analysis exist in considerable and irresolvable creative tension. The Cambridge School in this period defined the ontology of SSE at both secondary and university level. In this period primary practice was fundamentally focused on basic literacy, most students left school by the age of 14 and never experienced SSE.

\section{Phase 4 - Growth through Language - 1954 to 1989}

In 1954, James Britton a graduate of English Literature and secondary English teacher in outer London joined the University of London's Institute of Education, spending the rest of his long career there and becoming the most influential theorist of the field to this day. With other very notable figures such as Harold Rosen, Douglas Barnes and John Dixon, he became part of what is often called the London School (that is School of thought) and may be considered the key figure in the 'turn to language'. This was not a reinforcement of Phase 2 'Conventions and conditions', it was a partial rejection of the conventions of language seen as part of the establishment's dismissal of working class language and culture. It was also a move to elevate the importance of expression and creative uses of language seen as the capacity of all human beings, including children. Britton in particular championed the vital place of speaking and listening in the process of developing knowledge in all subjects, developing the idea of language across the curriculum (Cox, model 2] 
Turning to language did not displace literature but it did dislodge it from pre-eminence. Inevitably SSE must be understood as part of the history of schooling and the move over the $20^{\text {th }}$ century from establishing universal primary education to creating a secondary provision with increasing inclusiveness of all types of student but also for a longer period of adolescence. For the majority of the population this happened between 1945 and about 1980. The secondary sector for older school students i.e. aged 14-18, was the privileged spaces of the public schools (about $5 \%$ of the school population) and the grammar schools (20\%), and this was where the English Cultural Heritage and the production of elite readers of Leavis' aspiration were enshrined. But the rise of other kinds of school, particularly the secondary modern after the Second World War (for the 'other' $75 \%$ ) raised some profound questions about what SSE should become. There were many factors at play throughout the 1950s and 60s, for our purposes the most important were the emergence of new forms of mass media such as television, burgeoning popular youth culture, especially music, significant increases in immigrant populations and the concept of nationalisation as egalitarianism which led to the establishment of the comprehensive school and therefore the abolition (with a few exceptions) of the grammar/secondary modern binary.

\section{One seminal text Growth Through English}

All the theorists from The London group mentioned above produced important bodies of work, and Britton unquestionably having the greatest international reputation and influence, he wrote mostly about language and its development in children and young people. For our purposes Growth Through English, which is really a report on the seminal Dartmouth conference (see Goodwyn, 2017) provides an extraordinarily vivid snapshot of SSE in its emergent ontology of the 1960s, with a resonance that continues to this moment.

As outlined above, Dixon identified three dominant 'models' (his word) to English (SSE) in the 1960s. First, there was 'skills', this approach was about 'drills' and exercises undertaken to improve basic literacy and was marked by decontextualised use of language. Second came 'cultural heritage', the notion that there was a well defined high culture and that by passing on knowledge of this culture, students would become more civilised and unified nationally through an appreciation of their great heritage. However, Dixon's own proposal, based on the work of James Britton in particular, was for a 'personal growth' model. Dixon's emphasis was much more on processes than content, hence his 'quicksilver' metaphor.

Central to his model was the placing of the individual learner at the heart of English and through various processes involving language use, developing that individual. His approach was essentially a constructivist theory of learning, arguing that individuals create new knowledge and then order and consolidate this knowledge. His manifesto also included considerable attention to using drama as a learning medium especially elements like role play, again emphasising speaking and listening. Personal Growth is profoundly infused with the work of the US pragmatists with John Dewey a powerful (although unacknowledged) presence throughout Growth through English, and this association places SSE in the progressive 'camp' and with a mission for emancipation that continues to this day, however contested.

Dixon did not reject literature or high culture but he saw them, in their current formation, as having a negative impact as the students became too passive and the teaching too transmissive. He thus took a stand against the Leavisite tradition (usually categorised as the Cambridge school) which 
fundamentally viewed high culture as a form of literary salvation. He very much rejected the skills model because it was decontextualised and he placed a very strong emphasis on students using their own writing and local language. He was much concerned with nature of the city schools and drew much of his examples from London where he taught, giving rise to the tag of the 'London', as opposed to The Cambridge, School of English (Gibbons, 2017). It is important to note that the revised 1975 edition of Dixon's book adds a counterbalancing chapter where additional weight is given to communication and discursive writing, and slightly amends Personal Growth to have a more explicit social dimension.

The Personal Growth model, I would certainly argue, has remained the most quietly influential force in the community of practice itself, despite much criticism of it by some theorists, for example Hunter (Hunter, 1987, 1988). There has been much critique of Dixon's text and of the personal growth model, but it has not been displaced and was identified by Cox and his committee as central to English teaching in the late 1980s, twenty years after Growth through English first appeared. Dixon's achievement was to bring together much of the best thinking of the 1960s and to challenge the grammar school orthodoxy. His text was essentially a manifesto for change and provided a real catalyst that energised English teaching and still does. I would argue that the revised ontology of SSE, formulated in the 1960s, continues today in the existential domain of the classroom, despite all the colonising of the textual domain by officialdom of all kinds.

Between Dixon and Cox there was much debate and Barnes' Versions of English was especially important because it was much more research based. Dixon's evidence was almost exclusively of students' work, Barnes and his team focused on the teaching through observation. There were also more sociological studies of English, for example, Mathieson's influential The Preachers of Culture (Mathieson, 1975) which argued that Leavis' dogma was still central and that also remains partially true even now. Terry Eagleton, the famous, Marxist literary critic commented that all English teachers are Leavisites whether they know it or not (Eagleton, 1975)

The Cox models capture a shift in the subject paradigm which is still reflected in practice today. The full report contains a short, but very important, chapter on Information Technology and on Media Education. This chapter is eminently uncertain quite 'what to do' with these new areas but it is emphatic about their growing importance to society and to its young people. The Cox curriculum itself includes Media Education in English and this was its first real recognition (in England) as a part of formal schooling (Goodwyn, 1992b), encapsulated as Cultural Analysis; more evidence of the 'quicksilver' subject.

Cox started with Personal Growth because he had come to realise that this was at the heart of English teacher's beliefs. However, Cox and his committee also recognised that Cultural Heritage remained a real force in English and that most teachers related to it, often critically, but nevertheless it had a certain dominance and also a loyal following. The Adult Needs model is partly the Dixon skills model and partly what came to be the great Literacy paradigm of the late 1990s and beyond. The most important 'new' model was Cultural Analysis as it signalled the paradigm shift towards accepting the study of media, popular culture and to developing a critical approach to all texts. This was an expansive ontological shift, having knowledge about media texts was now important.

Clearly these 'models' are both complementary and contradictory but this is their collective strength and Cox was quite right to set them out in this way. Cox was, however, wrong about 'Cross 
curricular'. Although he was essentially right in recognising the powerful influence of the 1975 Bullock Report, A Language for Life, (DES, 1975), he was mistaken in thinking this was part of the English paradigm. My surveys of teachers and student teachers over 25 years (Goodwyn, 2011) are quite consistent in their findings, English teachers state that Language Across the Curriculum is a whole school approach and is chiefly important to teachers of other subjects who need to recognise their responsibility (as Bullock actually proposed) to monitor their own use of language in their teaching and to pay attention to helping their students develop as language users (Goodwyn, 1992a, Goodwyn and Findlay, 1999, Goodwyn, 2004).

\section{Phase 5: English in harmonious practice}

For a brief period of time, probably 1980-1992, the ontology of SSE was in a kind of alignment with all the various forces in a form of consensus, it existed, in other words, in a collective vision. The following elements were 'lined up'.

The fundamentally egalitarian comprehensive system was fully in place. In 1984, the new assessment system to fit with a comprehensive school, the GCSE, replacing 'o' levels and CSEs, was operational and drew heavily on the innovative practices of the CSE [the certificate developed for less academic students from the Secondary Modern Schools, that is the $80 \%$ of students who did not attend grammar schools. This model incorporated all the thinking of The London School, foregrounding Speaking and Listening, writing as expression, reading as personal response and growth, and it put assessment completely in the hands of teachers. Politically English teachers were seen as autonomous professionals and responsible for all aspects of student learning and 'outcomes' (not a word in use at the time). This autonomy included textual choice, with the Cox Report strongly advocating multi-cultural literature and a very wide range of texts including plenty of contemporary writers and non-fiction, supporting the use of media artefacts in the classroom. The only compulsory author was Shakespeare, something English teachers were very content with. This was also the last decade before the coming of Ofsted (The Office for Standards in Education, responsible for inspecting every school in the country every three years and pronouncing whether the school should continue or 'fail' and be closed) , The Teacher Training Agency (which regulated all teacher education), School League Tables (where all schools appeared in their local newspapers ranked by test results) etc. etc. The alignment was such that my research in 1990 (Goodwyn, 1992) found that while English teachers were deeply apprehensive about centralised control (and how right they were) they actually agreed with the spirit and the letter of the first National Curriculum for English, certainly secondary teachers believed in this version of SSE.

For primary teachers, the introduction in 1989 of the NC meant that suddenly there was something called English for ages 5-11. Their practice had always named what they did as 'language work', with the four modes incorporated in a very child centred pedagogy. This imposition was not welcomed and there is not much evidence of sudden change in primary schools (see Goodwyn and Fuller, 2011). The monolithic National Literacy Strategy, which would drive a juggernaut through primary education, was a few years away.

In this period reading and writing, speaking and listening were seen as equal dynamics in enabling the development of young people as future citizens in a participatory democracy; English was emancipatory. Most departments organised their classes into fully mixed ability groupings, while Maths departments stuck rigidly to ability setting. SSE was in a highly active period of development, 
the existential and textual domains were harmoniously aligned, with teachers allowed full creative engagement with curriculum, assessment and pedagogy, it was a Perrsonal Growth National Curriculum and a Personal Growth classroom existence.

\section{Phase 6: Building the Panopticon, the coming of control, conformity and self-regulation}

Between about 1992 and 2007 SSE became profoundly schizmatised and all alignment disappeared. In an ontological sense, SSE fragmented into three existences with differing epistemological stances. Beginning with the first revisions of the NCE as early as 1992, the state's version of SSE was increasingly of a nationalistic English, a highly formalised SSE, dominated by performance indicators for students and teachers, fiercely inspected by Ofsted; this is the version seen from the panopticon The panopticon concept originates with $19^{\text {th }}$ century English philosopher Jeremy Bentham, he designed a prison where every individual cell is separated and one guard in the centre of the structure can watch every single prisoner. The idea was developed by Foucault who saw it as the way state (or any) surveillance power structure induces self regulation in every individual within the sphere of the power..

Teachers have held on to their own, the second version, an ideological SSE. In their minds, it continued to be an emancipatory project imbued with Personal Growth. The third SSE existed uneasily in practice in constant tension between the demands of the state and the beliefs of the teachers. This can be easily pictured in the different practices being displayed in 'panopticon lessons' 'put on' for Inspectors and observations by Senior Management when compared to a 'real' and ordinary lesson (See Goodwyn, 2010). However, the effect of the panopticon, is to produce performative anxiety which creates a mode of self-regulation. The fragmentation of the school system, for example generating hundreds of academies 'free' from the National Curriculum for English (NCE) and no longer in a relationship with a local authority, means they are independent whilst still subject to Ofsted. But practice, version 3, seems to persist in a self-regulating mode.

In explaining this final period of the panopticon there are some key indicators. Two significant texts appeared in the 1980s, written by the 'old school' Her Majesty's Inspectors of Schools, these inspectors were viewed by the profession as critical friends, not the 'enemy', Ofsted inspectors were certainly viewed as the enemy (see Goodwyn, 2011a). The first text foreshadowed in its name English for Ages 5-16 (DES, 1984) and in tone, the various versions of the NCE from 1992 onwards, with its emphasis on formal language teaching and suggesting that some of the rigour of language study had been lost. However the pivotal document is in English for ages 5-16, a response (DES, 1986). Historically it was most unusual for HMI to write in response to criticisms and signalled the establishment's need to reinforce its arguments through the proxy of an 'independent' and respected institution - it might be argued that that experience began the process of developing Ofsted in its aggressive and punitive form in the nineties and noughties.

The response also recommended the project that became Language in the National Curriculum which itself came from the 'Investigation' led by John Kingman (a mathematician) which reported in 1988 as Knowledge About Language (DES, 1988) and was then overtaken by the sudden establishment of the Cox committee. For a fuller account, see Goodwyn 2011a. For (Applied) Linguists this was a very striking moment in the ontology of English and, perhaps, the promise of some recognition of what Linguistics might finally offer in SSE. What has actually happened is the 
growth of ' $A$ ' level English Language, and in that sense SSE has changed its ontological status but, I would argue, only marginally for 'mainstream' SSE 11-16.

Kingman argued for Knowledge About Language (KAL) and NOT a return to formal grammar teaching, this theme was supported by Cox and so the first NCE had a section on KAL as desirable but did not demand much knowledge of linguistics from students. However, it remains to this day a well known phenomenon that SSE teachers tend to have strong literary knowledge and relatively weak linguistic knowledge (See Myhill, Lines \& Watson, 2011), and what is often deemed an anxiety about grammar. Kingman's recommendations were largely adopted in 1988 and, despite the overtaking of that Report by the Cox Report in 1989, The Language In the National Curriculum (LINC) Project, led by Professor Ron Carter, was set up to improve the KAL of all SSE teachers in-service and in training and to develop supporting materials, this was broadly welcomed by the profession (Goodwyn, 2011b) and was part of the confluent alignment of the time. The training was somewhat problematic, being a 'cascade model' where one teacher from each English department received training from regional advisors and then was supplied with all the emergent materials. There was also a strand for Initial Teacher Training, enthusiastically adopted by University PGCE tutors, this author being one.

The work of LINC was completed by 1992 but its model of a fundamentally sociolinguistic approach to texts and a focus on criticality rather than formal grammar knowledge led to a most extraordinary political reaction from the contemporary right wing government and the materials were literally banned from schools with much media furore about 25 million pounds being wasted and leading to a Panorama documentary investigating what happened. This act remains an outrageous intervention by the state and a barbaric piece of censorship; it is largely forgotten and hurriedly photocopied versions of the LINC materials now gather dust, if they exist at all. What might have led to an ontological revision of SSE with a new model of English, the KAL model, that teachers would have welcomed, was instead an aborted project, signalling, yet again, the state's intention to control SSE and its teachers.

The final leg on this journey begins in 1997, with the bringing in of New Labour's flagship policy, The National Literacy Strategy and ends in 2011, when it, and its secondary companion, The Framework for English (FWE), were discontinued. It was a remarkable sign of the (ironically) higher status of English, compared to Maths (in England), that the parallel National Numeracy Strategy was a modest and uncontentious affair. For our purposes the FWE was another element in the schizmatisation of SSE and it was the period when SSE teachers - with no irony - became opposed to 'Literacy'. There is extensive research (Goodwyn, 2011c) about the way SSE teachers reviled and resisted the dogmatic approaches of the FWE, quite liked the materials produced, but found nothing new in them and began to live in the three ontologies that still persist.

\section{PG and SSE teachers}

The other major finding of my surveys over 25 years is that Personal Growth remains the most important model to English teachers regardless of age and experience. They generally put Cultural Heritage last and Cultural Analysis and Adult Needs close together but they do 'recognise' that these models capture what goes on in the community of their practice. When asked to identify what the official curriculum demands, they often put Cultural Heritage first, illustrating perfectly the difference between the prescribed form of English and its lived reality in practice. Surveys are, of 
course, self report, and might well reflect espoused models rather than realities, nevertheless, their consistency is remarkable and there has been no major empirical study to challenge these findings. An interesting critique is contained in Marshall's English Teachers - The Unofficial Guide: researching the philosophies of English Teachers (2000). One observation-based study, English in Urban Classrooms (Kress et al, 2005), brought a valuable multimodal perspective to understanding how SSE teachers carry out their practice with some attention to SSE in its embodied present tense rendition.

\section{Closing remarks}

I will not summarise what is already a summary. However, SSE (Secondary Subject English) in England has clearly passed through several formative phases and fundamentally has consistently expanded its 'territory' as the number of models has increased to four, Personal Growth, Cultural Analysis, Adult Needs and Cultural Heritage. I argue that its existence in the early part of the twenty first century has, for its teachers, been fragmented into three, there is (1) the state's, mostly textual version, (2) the inner, ideological beliefs of its teachers and then (3) the messy reality of practice where these two ontologies interact under a panopticon gaze, enforced externally but also acting as a self-regulating force. Compared to the 1980s, SSE is a much less emancipatory project and has actually shrunk in scope and ambition. For example, in 2000 the revised NC included several references to the importance of the moving image, all of which have been removed from the current and statutory NCE. Simultaneously, the NCE has no longer any force in Academies and Free Schools, but this neoliberal policy has not produced a flourishing of bold and innovative teaching. However, this current phase will be just that, a phase. If educational policy can recapture an egalitarian and emancipatory vision, not social mobility but social justice, then English teachers will once more aim for the personal growth of each student and the collective benefits of social empowerment for the nation, perhaps a phase 8, of Emancipation, agency and social justice? (Goodwyn, 2017, 2018)

\section{References}

Barnes, D., Britton, J. \& Rosen, H. (1971). Language the Learner and the School. Harmondsworth, Penguin.

Barnes, D. \& Barnes, D. (1984) Versions of English. London, Heinemann.

Cox, B. (1991). Cox on Cox: An English Curriculum for the 1990s, London, Hodder and Stoughton.

Cox.B. (1992) The Great Betrayal: memoirs of a life in Education, London, Chapmans publishing.

DES, Department for Education (2018). https://www.gov.uk/government/publications/nationalcurriculum-in-england-english-programmes-of-study.

DES (1989). English for ages 5-16, London, HMSO.

DES (1988). Knowledge About Language, London, HMSO.

DES. (1984). English for ages 5-16. London, HMSO.

DES. (1986). Responses to English for ages 5-16. London, HMSO. 
DES. (1975). A Language for Life, (known as The Bullock Report) London, HMSO.

Departmental Committee of the Board of Education. (1921.) The Teaching of English in England (The Newbolt Report). London, His Majesty's Stationery Office.

Dixon, J. (1975). Growth through English: set in the perspective of the seventies. Oxford, Oxford University Press.

Eagleton, T. (1975). Literary Theory an Introduction, Oxford, Blackwells

Gibbons, S. (2017) English and its Teachers: A History of Policy, Pedagogy and Practice. Abingdon, Routledge.

Goodwyn, A., Durrant, C., Sawyer, W., Zancanella, D. \& Scherff, E. (2018). (Eds.). The Future of English teaching worldwide and its histories: celebrating 50 years from the Dartmouth conference. London, Routledge

Goodwyn, A. (2018)_From Personal Growth [1966] to Personal Growth and Social Agency [2016] proposing an invigorated model for the $21^{\text {st }}$ Century. In A.Goodwyn, C.Durrant, W.Sawyer \& L. Scherff. (Eds.). The Future of English teaching worldwide and its histories: celebrating 50 years from the Dartmouth conference. London, Routledge.

Goodwyn, A. (2017). From Personal Growth (1966) to Personal Growth and Social Agency proposing an invigorated model for the 21st Century, English in Australia, 52(1), 66-73.

Goodwyn, A. (2016). Still growing after all these years? The Resilience of the 'Personal Growth model of English' in England and also internationally. English Teaching, practice and critique. 15(2), 7-21.

Goodwyn, A. (2011a). The impact of the Framework for English: teachers' struggle against 'informed prescription'. In A. Goodwyn, A \& C. Fuller, C. (Eds.). The Great Literacy Debate, (pp. 117-135) London, Routledge Falmer.

Goodwyn, A. (2011b). Becoming an English Teacher: Identity, Self knowledge and Expertise. In J. Davison \& J. Moss, J. [Eds.) Debates in English, (pp.18-36), London, Routledge.

Goodwyn, A \& Fuller, C. (Eds.) (2011c) The Great Literacy Debate,. London, Routledge.

Goodwyn, A. (2010). The Expert Teacher of English. London, Routledge.

Goodwyn, A., \& Findlay, K. (1999). The Cox Models Revisited: English Teacher's Views of their Subject and the National Curriculum, English in Education. 33 (2), 19-31.

Goodwyn, A. (2004). Literacy versus English: a professional identity crisis. In A. Goodwyn \& A. Stables (Eds.). Learning to Read Critically in Language and Literacy Education, (pp. 192-205), London: Sage.

Goodwyn, A. (2003). Literacy or English: The struggle for the Professional Identity of English Teachers in England. In Homer, D., Doecke, B. \& Nixon, H., (Eds.). English Teachers at Work: Narratives, Counter-narratives and Arguments (pp. 123-135). Australian Association for the Teaching of English /Interface. Kent Town, South Australia: Wakefield Press 
Goodwyn, A. (1992a). Theoretical Models of English Teaching, English in Education, 26 (3), 4-10.

Goodwyn, A. (1992b). English Teaching and Media Education, Buckingham: Open University Press.

Hilliard, C. (2012). English as a Vocation: The Scrutiny Movement, Oxford, Oxford University Press.

Hunter, I. (1987). Culture, education, English: Building "the principal scene of the real life of children" Economy and Society, 16, 568-88.

Hunter, I. (1988). Culture and government: The emergence of literary education. London, Macmillan.

Kress, G., Jewitt, C., Bourne, J., Hardcastle, J., Jones, K. \& Reid, E.(2003). English in Urban Classrooms: A Multimodal Perspective on Teaching and Learning. Oxford, Routledge.

Leavis, F.R. (1962). The Great Tradition, Harmondsworth, Penguin.

Leavis, F.R. \& Thompson, D. (1933). Culture and Environment. London, Chatto and Windus.

Marshall, B. (2000). English Teachers - the Unofficial Guide: Researching the Philosophies of English Teachers. London: Routledge

Mathieson, M. (1975). The Preachers of Culture: A Study of English and its Teachers. Oxford, George Allen and Unwin.

Myhill, D., Lines, H., Watson, A. \& Jones, S. (2011). Rethinking Grammar: The Impact of Embedded Grammar Teaching on Students' Writing and Students' Metalinguistic Understanding. Research Papers in Education, 27(2) pp.139-166.

OECD (2015). Volume I, Excellence and Equity in Education, summarises student performance in PISA 2015, and examines inclusiveness and fairness in participating education systems, http://dx.doi.org/10.1787/9789264266490-en.

Richards, I.A. (1924). The Principles of Literary Criticism, London, Routledge and Kegan Paul.

Richards, I.A. (1929). Practical Criticism. London, Routledge and Kegan Paul.

Rosenblatt, L. (1938/1970). Literature as Exploration. New York MLA.

Sampson, G. (1921). English for the English. Cambridge, Cambridge University Press.

Shulman, L.S. (1986). Those who understand: Knowledge Growth in Teaching. Educational Researcher, 15, (2) pp.4-14.

Shulman, L.S. (1987). Knowledge and Teaching: Foundations of the New Reform. Harvard Educational Review. 57 (1) pp.1-22. 